\title{
The effect of comorbid personality disorder on depression outcome after short-term psychotherapy in a randomised clinical trial
}

\author{
David Koppers, Marit Kool, Henricus Van, Ellen Driessen, Jaap Peen and Jack Dekker
}

\section{Background}

Time-limited psychotherapy for depression is effective. However, comorbid personality disorders affect therapy outcomes negatively. Studies of follow-up effects and results relating to the influence of comorbid personality disorder and treatment modality are scarce.

\section{Aims}

To determine the influence of comorbid personality disorder and treatment modality on outcomes after cognitive-behavioural therapy (CBT) or short-term psychodynamic supportive psychotherapy (SPSP) for depression.

\section{Method}

This study draws on data from a previously published randomised clinical trial contrasting SPSP and CBT for depression (both 16 sessions). We compared the effectiveness of these psychotherapies for patients with and without personality disorder $(n=196)$. The primary measure was depression outcome; the secondary measurements were interpersonal functioning and quality of life. Collected data were analysed using multilevel analysis. Trial registration: ISRCTN31263312 (http://www.controlled-trials.com).

\section{Results}

Although participants with and without comorbid personality disorder improved at treatment termination $(d=1.04,95 \% \mathrm{Cl}$ $0.77-1.31$ and $d=1.36,95 \% \mathrm{Cl} 0.97-1.76$, respectively) and at follow-up $(d=1.15,95 \% \mathrm{Cl} 0.87-1.43$ and $d=2.12,95 \% \mathrm{Cl}$ 1.65-2.59 respectively), personality disorder had a negative effect on depression outcome at both measurement points
$(P<0.05)$. A similar negative effect on interpersonal functioning was no longer apparent at follow-up. Comorbid personality disorder had no influence on social functioning or quality of life outcomes, irrespective of treatment modality.

\section{Conclusions}

CBT and SPSP contribute to the improvement of depressive symptoms and interpersonal problems in depressed patients with and without comorbid personality disorder. Both treatments are an effective first step in a stepped care approach, but - given remaining levels of depression in patients with personality disorder - they are probably inadequate for large numbers of patients with this comorbidity.

\section{Declaration of interest}

None.

\section{Keywords}

Comorbidity; depressive disorders; outcome studies; personality disorders; randomised controlled trial.

\section{Copyright and usage}

(C) The Royal College of Psychiatrists 2019. This is an Open Access article, distributed under the terms of the Creative Commons Attribution-NonCommercial-ShareAlike licence (http://creativecommons.org/licenses/by-nc-sa/4.0/), which permits non-commercial re-use, distribution, and reproduction in any medium, provided the same Creative Commons licence is included and the original work is properly cited. The written permission of Cambridge University Press must be obtained for commercial re-use
Most evidence about the effectiveness of treatment for depression is based on short-term psychotherapies such as cognitive-behavioural therapy (CBT), short-term psychodynamic therapy and interpersonal therapy. That body of evidence indicates that effect sizes at treatment termination ${ }^{1,2}$ and at follow-up ${ }^{3,4}$ are high but that remission rates are very low, ${ }^{5}$ especially in groups presenting with more complex clinical pictures. Furthermore, differences in effectiveness were found between these therapies. ${ }^{5}$ The low remission rates in depressed patients can be explained, at least in part, by the relatively high prevalence of comorbid personality disorders in these patients. ${ }^{6}$ Indeed, a large meta-analysis ${ }^{7}$ demonstrated that comorbid personality disorders more than doubled the risk of a poor outcome (odds ratio $=2.16, \mathrm{CI} 1.83-2.56$ ), irrespective of treatment modality. Furthermore, even though most studies included in this meta-analysis looked at pharmacotherapy with antidepressants, this effect was also apparent in the psychotherapy studies included. Newton-Howes suggests that this effect could be related to the untreated personality pathology. ${ }^{7}$ However, there were also psychotherapy studies which failed to find a negative effect of personality disorder on treatment outcome. ${ }^{8,9}$ The strong treatment focus of the examined therapies (in other words, CBT) on depression may explain why the presence of comorbid personality disorder had no effect on that treatment focus.
In general, follow-up studies indicate that effects are relatively stable in samples of depressed patients despite the major fluctuations that characterise the course of this disorder. ${ }^{10}$ However, it is not clear to what extent the effect of therapy is maintained in patients with comorbid personality disorder. ${ }^{11}$ It is also unclear what improvement can be expected in this patient group on personality parameters in short-term psychotherapies and whether an improvement of that kind will be needed for therapy to result in a sustained effect on depression. In addition, the persistence of poor social and interpersonal functioning is likely to contribute to susceptibility to recurrence of depression in this comorbid group. However, to our knowledge, no studies have yet been conducted of how personality disorder affects 1 year follow-up outcomes in depressed patients after short-term psychotherapies.

This study investigates the role of personality disorder in a large clinical sample of depressed patients treated with either CBT or short-term psychodynamic supportive psychotherapy (SPSP). The research questions are as follows.

(a) Do depressed patients with and without personality disorder differ in their sociodemographic characteristics and in their depressive symptoms? 
(b) What is the difference in therapy effect in depressed patients with and without personality disorder at the end of treatment and at follow-up?

(c) Does the treatment modality (CBT or SPSP) affect the treatment outcome at treatment termination and follow-up?

\section{Method}

\section{Design}

This study draws on data from a randomised clinical trial looking at the effectiveness of a psychodynamic approach (SPSP) and CBT for depression. The study was approved by the Dutch Association of Medical-Ethics Committees for mental health organisations. For more information about the trial design, eligibility criteria, determination of the sample, harmful or unintended effects of the sample, randomisation procedures and interventions, refer to Driessen et al. ${ }^{12}$ Trial registration: ISRCTN31263312 (http://www. controlled-trials.com).

\section{Interventions}

Both psychotherapy conditions included 16 individual sessions over a period of 22 weeks and were conducted on the basis of published treatment manuals. ${ }^{13,14} \mathrm{CBT}$ is based on the principles of Beck ${ }^{15}$ and consists of behavioural activation and cognitive restructuring based on a session-by-session protocol with homework assignments.

SPSP was used to represent the psychodynamic intervention. This modality involves a more open patient-therapist dialogue that uses supportive and insight-facilitating techniques to address the emotional background to the depression by discussing current relationships, internalised past relationships and intrapersonal patterns.

Patients with severe depression, as determined by a Hamilton Rating Scale for Depression (HRSD) ${ }^{16}$ score $\geq 24$ at baseline, and moderately depressed patients at baseline who developed severe symptoms during psychotherapy were offered additional antidepressant medication.

\section{Participants}

The main diagnosis in the 341 patients in the original randomised controlled trial ${ }^{12}$ was major depressive episode according to DSM-IV criteria as assessed with the MINI-International Neuropsychiatric Interview-Plus (MINI-Plus). ${ }^{17}$ Other inclusion criteria were a $\mathrm{HRSD}^{16}$ score $\geq 14$ and age $18-65$ years. Exclusion criteria were actual presence of psychotic symptoms or bipolar disorder, severe suicidality, substance misuse disorders, pregnancy, inability to meet trial demands, and use of psychotropic or other medications that might influence mental functions. The participants were recruited from three psychiatric out-patient clinics in Amsterdam, the Netherlands, during the period April 2006 to December 2009. One year follow-up assessments were conducted from April 2007 to January 2011.

\section{Measurements}

\section{Personality disorder measure}

Personality disorder diagnoses were assessed using the International Personality Disorder Examination - Self report (IPDE-SR). This is a self-report questionnaire based on the IPDE, ${ }^{18}$ a semi-structured interview for personality disorders. The psychometric qualities of the Dutch version of the IPDE-SR are moderately reliable (Cronbach's $\alpha=0.66$ ), and its temporal stability is also moderate $(r=0.62){ }^{19}$ The IPDE-SR consists of 174 questions in seven topics in line with the IPDE semi-structured interview. Most
IPDE questions have a single corresponding item in the selfreport version. The questions are scored on a three-point Likert scale: $2=$ true, $1=$ uncertain and $0=$ false, resulting in both dimensional scores and diagnoses. The dimensional score is calculated for each personality disorder by counting the number of criteria met (as 'true' statements) for each disorder. As the prevalence of personality disorders is overestimated by a factor of 2.5 in comparison with a semi-structured clinical interview (e.g. IPDE), the IPDE-SR is considered suitable as a screening instrument for personality disorder but not as a diagnostic tool. ${ }^{20}$

As $196(57.5 \%)$ participants of the original sample $(n=341)$ filled in the IPDE-SR, we made a representative analysis of the research sample in order to test whether the group of patients with an IPDE-SR was an accurate representation of the total sample.

A few significant differences were found between patients with an IPDE-SR and those without. Patients who filled in an IPDE-SR lived alone more often, received social security benefits less often, had a higher level of education, higher incomes, and a greater number of previous depressive episodes; fewer had HRSD scores $>24$, and the mean IDS score was lower. No differences between participants with and without an IPDE-SR were found in terms of the following characteristics: gender, cultural background, marital status, interpersonal relationships (Outcome Questionnaire (OQ) subscale for interpersonal relations at baseline), social role-playing (OQ subscale for social role playing at baseline) and quality of life (EuroQol (EQ)-5D at baseline); comorbid dysthymia (as determined by the MINI-plus), prior treatment for current depressive episode and duration of the present episode.

\section{Primary outcome measures}

Depression severity and the course of depression were measured with the HRSD. ${ }^{16}$ This is a structured interview consisting of 17 items that is designed to quantify the severity of depressive symptoms in patients already diagnosed with a depressive disorder. HRSD scores were established using the Dutch scoring manual: ${ }^{21}$ its reliability and validity are good. ${ }^{22}$ The independent assessors were research employees who, in order to promote interrater reliability, engaged in $1 \mathrm{~h}$ peer supervision sessions twice weekly at which audio-taped interviews were discussed. The average intraclass correlation coefficient for 46 audiotaped assessments scored by multiple assessors was $0.97 .^{12}$

Depression severity from the patient's point of view was assessed using the Inventory of Depressive Symptomatology, SelfReport (IDS-SR). ${ }^{23}$ This self-report questionnaire was designed to measure specific signs and symptoms of depression in in-patients and out-patients. The scale consists of 28 items in five dimensions: vegetative symptoms, cognitive changes, mood disturbance, endogenous symptoms and anxiety symptoms. Each of the items is rated from 0 to 3 and is equally weighted in the total score, reflecting the subjective severity of depressive symptoms. The IDS-SR has good internal consistency, concurrent validity, and construct validity. $^{23}$

Both depression measures, the HRSD and IDS-SR, were found to be reliable at baseline assessment (Cronbach's $\alpha=0.75$ and 0.78 , respectively).

\section{Secondary outcome measures}

Interpersonal functioning was measured with the subscale Interpersonal Relations and Social Role Functioning of the OQ-45. ${ }^{24}$ These scales consist of 11 items and nine items respectively, each rated on a five-point Likert scale from 0 (never) to 4 (almost always). The reliability and validity of the Dutch version of the OQ- 45 have been demonstrated. ${ }^{25}$ 


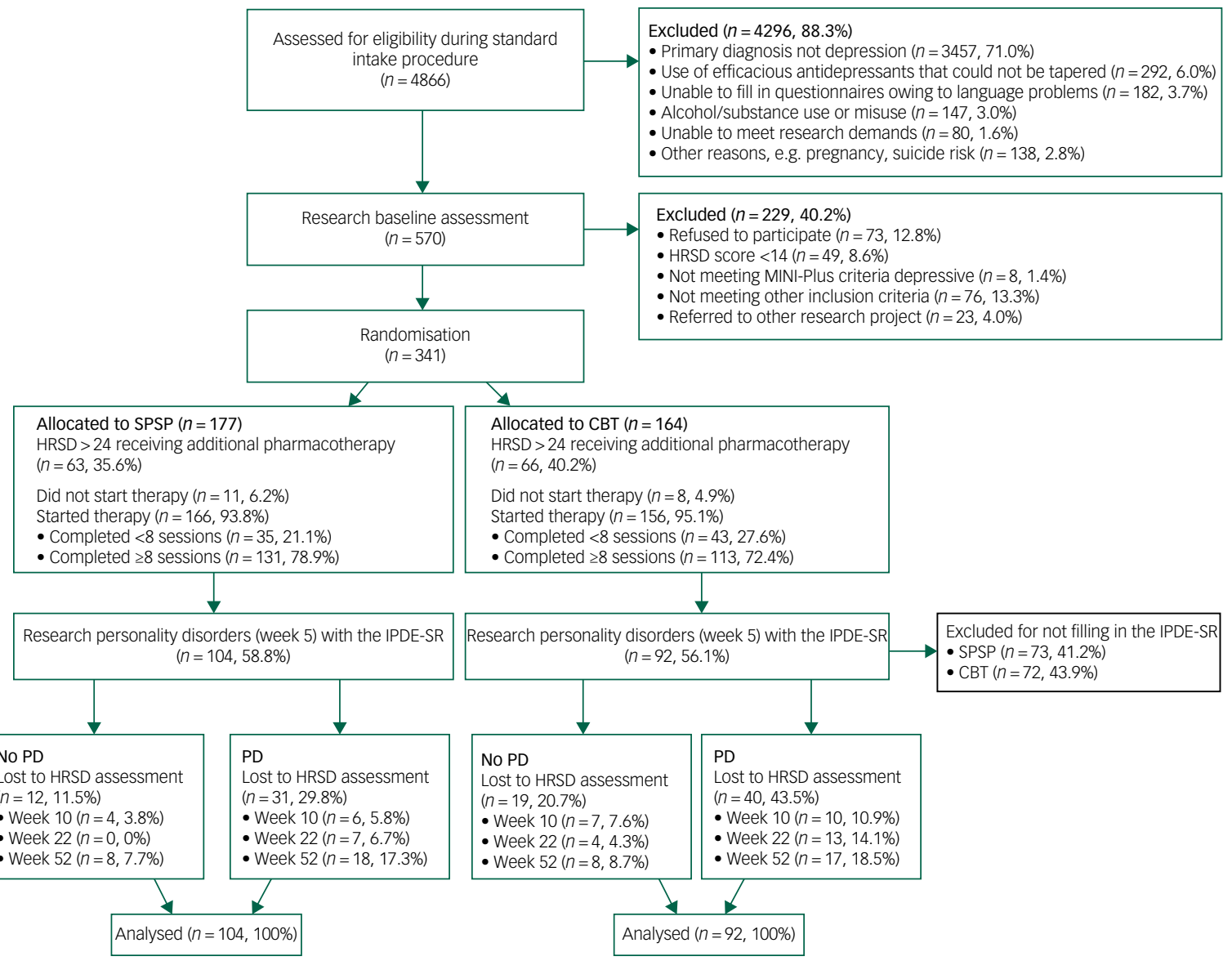

Fig. 1 Flowchart of participants through the different research phases.

HRSD, Hamilton Rating Scale for Depression; MINI-Plus, MINI-International Neuropsychiatric Interview-Plus; SPSP, short-term psychodynamic supportive psychotherapy; CBT, cognitive-behavioural therapy; IPDE-SR, International Personality Disorder Examination - Self report; PD, personality disorder.

Quality of life was measured using the EQ-5D. ${ }^{26}$ This standardised, non-disease-specific self-report instrument is designed to describe health states. The questionnaire consists of five items covering the following health dimensions: mobility, self-care, usual activities, pain or discomfort, and anxiety or depression. The items are structured as follows: $1=$ no problems, $2=$ some problems, 3 = extreme problems. The validity and reliability of the EQ-5D are acceptable. ${ }^{27}$

The IPDE-SR was assessed at week 5, while all outcome measures were assessed at baseline, during treatment (week 10), at the end of treatment (week 22) and at follow-up (week 52).

\section{Statistical methods}

A post hoc power analysis in G-power $(\alpha=0.05,1-\beta=0.80)$ for a repeated-measures design revealed that the available 196 participants (intention-to-treat) were enough to detect an outcome difference (Cohen's $d=0.17$ ) between the two patient groups and the treatment condition (SPSP or CBT).

The baseline characteristics of personality disorder and nonpersonality disorder patients were compared using $\chi^{2}$-tests (categorical variables) and analysis of variance (continuous variables).

Given the hierarchical data structure, linear mixed model analyses were used for the analysis of the repeated continuous outcomes. These analyses were conducted using a three-level structure (therapist, patient and repeated measures). To control for possible confounding, we added the following covariates: treatment condition, the baseline score of the dependent outcome variable and the number of previous episodes. The first analysis tested differences between personality disorder and non-personality disorder patients at each measurement point and also over all measurement points together. In the second analysis, the interaction between treatment condition and personality disorder/non-personality disorder was tested at each measurement point and over all measurement points together. In addition to these analyses, prepost effect sizes with 95\% confidence intervals are presented. These within-group effect sizes are stated as Cohen's $d$ corrected by the correlation between the paired measurements $\left(d / \operatorname{sqrt}(1-r){ }^{28}\right.$

The linear mixed model analyses were performed in MLwiN version 2.25. All other analyses were performed in SPSS version 22.0 .

\section{Results}

\section{Participants}

Figure 1 shows the flow of the patients in the study. A total of 4866 patients were assessed for eligibility during a standard intake procedure: $570(11.7 \%)$ were found to be potentially eligible and were invited for baseline assessment; 341 of these patients were randomised (SPSP: 177, CBT: 164).

Of these 341 patients, 196 patients $(57.5 \%)$ completed the IPDE-SR (SPSP: 104, CBT: 92). Ten of these patients (9.6\%) in the SPSP condition and $17(18.5 \%)$ in the CBT condition were lost to 


\begin{tabular}{|c|c|c|c|c|}
\hline Variable & & No PD $(n=63)$ & $\mathrm{PD}(n=133)$ & Total $(n=196)$ \\
\hline \multicolumn{5}{|l|}{ Demographics } \\
\hline Gender $(n, \%)$ & Male & $17(27)$ & 45 (34) & $62(32)$ \\
\hline Cultural background $(n, \%)$ & Non-Western & $22(35)$ & $50(38)$ & $72(37)$ \\
\hline \multirow[t]{5}{*}{ Marital Status $(n, \%)$} & Married & $15(24)$ & $34(26)$ & $49(25)$ \\
\hline & Divorced & $10(16)$ & $20(15)$ & $30(15)$ \\
\hline & Widowed & $3(5)$ & 4 (3) & $7(4)$ \\
\hline & Never married & $35(56)$ & $74(56)$ & 109 (56) \\
\hline & Other & $0(0)$ & $1(1)$ & $1(1)$ \\
\hline \multirow{3}{*}{ Living situation $(n, \%)$} & Living with at least one other person & $37(59)$ & $77(58)$ & $114(59)$ \\
\hline & Living alone & $23(37)$ & 51 (39) & $74(38)$ \\
\hline & Other & $3(5)$ & $4(3)$ & $7(4)$ \\
\hline \multirow[t]{3}{*}{ Employment status ( $n, \%)$} & Employed/student & $32(51)$ & $52(44)$ & $89(46)$ \\
\hline & Sickness benefits/social security benefits & $26(41)$ & $56(43)$ & $82(42)$ \\
\hline & Other & $5(8)$ & $18(14)$ & $23(12)$ \\
\hline \multirow[t]{4}{*}{ Educational level $(n, \%)$} & Low & $13(21)$ & $27(21)$ & $40(21)$ \\
\hline & Intermediate & 22 (35) & $60(46)$ & $82(42)$ \\
\hline & High & 24 (38) & $42(32)$ & $66(34)$ \\
\hline & Other & $4(6)$ & $3(2)$ & $7(4)$ \\
\hline Main income before taxes & $\leq 1273$ a month & $18(32)$ & 44 (39) & $62(37)$ \\
\hline \multicolumn{5}{|l|}{ Symptom severity } \\
\hline HRSD score, mean (s.d.) ${ }^{a}$ & & $21.73(4.36)$ & $23.20(5.28)$ & $22.72(5.04)$ \\
\hline IDS, mean (s.d.) $)^{\mathrm{b}}$ & & $37.83(8.78)$ & $43.60(9.88)$ & $41.62(9.88)$ \\
\hline $\mathrm{OQ}$ interpersonal relations, mean (s.d.) ${ }^{c}$ & & $16.41(6.18)$ & $21.92(5.16)$ & $20.31(6.00)$ \\
\hline $\mathrm{OQ}$ social role functioning, mean (s.d.) ${ }^{\mathrm{d}}$ & & $14.17(5.24)$ & $16.95(5.21)$ & $16.02(5.37)$ \\
\hline HRSD baseline >24 & & $16(25)$ & $47(35)$ & $63(32)$ \\
\hline \multicolumn{5}{|l|}{ Depression characteristics } \\
\hline \multirow[t]{5}{*}{ Duration present episode $(n, \%)$} & Less than 6 months & $17(27)$ & $31(23)$ & $48(25)$ \\
\hline & 6 months to 1 year & $14(22)$ & $38(29)$ & $52(27)$ \\
\hline & 1 to 2 years & $10(16)$ & $12(9)$ & $22(11)$ \\
\hline & More than 2 years & $19(30)$ & $39(29)$ & $58(30)$ \\
\hline & Unknown & $3(5)$ & $13(10)$ & $16(8)$ \\
\hline Prior treatment for current depressive episode $(n, \%)$ & Yes & $21(33)$ & $49(37)$ & $70(36)$ \\
\hline \multirow[t]{3}{*}{ Number of prior depressive episodes $(n, \%)^{\mathrm{e}}$} & None & $25(40)$ & $32(24)$ & $57(29)$ \\
\hline & One & $6(10)$ & $25(19)$ & $31(16)$ \\
\hline & Two or more & $32(51)$ & $76(57)$ & $108(55)$ \\
\hline Comorbid dysthymia $(n, \%)$ & Yes & $17(29)$ & $48(39)$ & $65(36)$ \\
\hline
\end{tabular}

HRSD assessments midway through the treatment (week 10). The same happened with seven patients (6.7\%) in the SPSP condition and $17(18.4 \%)$ in the CBT condition at the end of the treatment (week 22). At follow-up (week 52), 26 patients (25\%) in the SPSP condition and $25(27.2 \%)$ in the CBT condition were lost to HRSD assessments.

At follow-up, 71 patients (49\%) had received additional therapy with no difference between the personality disorder and non-personality disorder groups $\left(\chi^{2}=1.328\right.$, d.f. $\left.=1, P=0.25\right)$.

\section{Baseline characteristics}

Sixty-three (32.1\%) of the 196 participants who completed the IPDE-SR had no personality disorder as determined with the IPDE-SR, 38 (19.4\%) had one personality disorder, 22 (11.2\%) had two personality disorders and $73(37.2 \%)$ had three or more personality disorders. The most common disorders were avoidant personality disorder (63.2\%), paranoid personality disorder (60.9\%) and obsessive-compulsive disorder (51.1\%). Antisocial personality disorder (5.3\%), narcissistic personality disorder (9.8\%) and schizotypal personality disorder $(15.0 \%)$ were less common.

The demographic, social and clinical characteristics of the sample are shown in Table 1. There were no differences between the sociodemographic characteristics of patients with and without personality disorder. The duration of the present episode was also similar in both groups. However, patients with comorbid personality disorder had a higher level of self-reported severity of depression $(F=14.73$, d.f. $=1, P<0.01)$, and a trend was found indicating higher HRSD mean scores for depressed patients with personality disorder $(F=3.67$, d.f. $=1 P=0.06)$. Furthermore, more previous depressive episodes were found in patients with comorbid personality disorder $\left(\chi^{2}=6.23\right.$, d.f. $\left.=2, P=0.04\right)$, as well as more problems in interpersonal relationships $(F=28.00$, d.f. $=1, P<0.01)$ and social functioning $(F=9.09$, d.f. $=1, P<0.01)$ at baseline.

\section{Effect of personality disorders on depression outcome}

Table 2 shows the mean outcome scores at mid-treatment (10 weeks), at treatment termination (week 22) and at 30 weeks follow-up (week 52), as well as pre-post treatment effect sizes and pre-treatment-follow-up effect sizes. At each time point, multilevel analyses were conducted to determine the mean differences between depressed patients with and without personality disorder after controlling for covariates, treatment condition, previous depressive episodes and HRSD score at baseline.

As can be seen in Table 2, both patient groups improved in terms of depression, interpersonal and social role functioning, and 


\begin{tabular}{|c|c|c|c|c|c|c|c|c|c|c|}
\hline \multirow[b]{2}{*}{ Outcome measure } & \multicolumn{3}{|c|}{ No personality disorder } & \multicolumn{3}{|c|}{ Comorbid personality disorder } & \multicolumn{3}{|c|}{ Total } & \multirow{2}{*}{$\begin{array}{c}\text { Comorbid personality } \\
\text { disorder (yes/no) } \\
\text { Estimated mean } \\
\text { difference (s.e.) }\end{array}$} \\
\hline & $\begin{array}{l}\text { Mean } \\
\text { (s.d.) }\end{array}$ & $N$ & $\begin{array}{l}\text { Effect size } \\
d(95 \% \mathrm{Cl})\end{array}$ & $\begin{array}{l}\text { Mean } \\
\text { (s.d.) }\end{array}$ & $N$ & $\begin{array}{l}\text { Effect size } \\
d(95 \% \mathrm{Cl})\end{array}$ & $\begin{array}{l}\text { Mean } \\
\text { (s.d.) }\end{array}$ & $N$ & $\begin{array}{l}\text { Effect size } \\
d(95 \% \mathrm{Cl})\end{array}$ & \\
\hline \multicolumn{11}{|l|}{ HRSD } \\
\hline Baseline & $21.73(4.36)$ & 63 & & $23.20(5.28)$ & 133 & & $22.72(5.04)$ & 196 & & $-1.19(1.08)$ \\
\hline Week 10 & $15.58(8.33)$ & 52 & & $18.25(8.24)$ & 117 & & $17.43(8.33)$ & 169 & & $-2.89(1.15)^{\star}$ \\
\hline Week 22 & $13.20(7.79)$ & 59 & $1.70(1.28-2.12)$ & $15.69(8.97)$ & 113 & $1.31(1.02-1.60)$ & $14.84(8.64)$ & 172 & $1.44(1.20-1.67)$ & $-2.37(1.12)^{\star}$ \\
\hline Week 52 & $10.38(6.48)$ & 47 & $2.40(1.87-2.93)$ & $14.62(9.67)$ & 98 & $1.46(1.14-1.77)$ & $13.25(8.96)$ & 145 & $1.70(1.43-1.97)$ & $-4.47(1.21)^{\star}$ \\
\hline \multicolumn{11}{|l|}{ IDS } \\
\hline Baseline & $37.83(8.78)$ & 61 & & $43.60(9.88)$ & 117 & & $41.62(9.88)$ & 178 & & $-1.59(1.65)$ \\
\hline Week 10 & $27.83(13.25)$ & 49 & & $35.53(14.77)$ & 102 & & $33.03(14.70)$ & 151 & & $-4.66(1.83)^{\star}$ \\
\hline Week 22 & $22.24(13.10)$ & 50 & $1.78(1.31-2.24)$ & $32.16(16.41)$ & 91 & $1.31(0.98-1.64)$ & $28.64(16.00)$ & 141 & $1.48(1.21-1.75)$ & $-4.99(1.85)^{*}$ \\
\hline Week 52 & $16.45(12.01)$ & 39 & $3.11(2.44-3.78)$ & $26.89(16.55)$ & 64 & $1.53(1.12-1.94)$ & $22.93(15.78)$ & 103 & $1.94(1.60-2.28)$ & $-5.58(2.10)^{\star}$ \\
\hline \multicolumn{11}{|c|}{ OQ interpersonal relations } \\
\hline Baseline & $16.41(6.18)$ & 39 & & $21.92(5.16)$ & 95 & & $20.31(6.00)$ & 134 & & $-1.68(0.98)$ \\
\hline Week 10 & $13.39(6.29)$ & 45 & & $19.66(7.12)$ & 95 & & $17.64(7.45)$ & 140 & & $-3.96(1.11)^{\star}$ \\
\hline Week 22 & $11.97(6.04)$ & 35 & $0.98(0.40-1.55)$ & $18.57(6.90)$ & 63 & $0.69(0.29-1.08)$ & $16.21(7.30)$ & 98 & $0.78(0.46-1.11)$ & $-4.11(1.19)^{*}$ \\
\hline Week 52 & $11.13(6.63)$ & 23 & $0.74(0.07-1.42)$ & $16.61(7.70)$ & 36 & 1.37 (0.81-1.93) & $14.47(7.73)$ & 59 & $1.06(0.63-1.48)$ & $-0.91(1.47)$ \\
\hline \multicolumn{11}{|c|}{ OQ social role functioning } \\
\hline Baseline & $14.17(5.24)$ & 48 & & $16.95(5.22)$ & 96 & & $16.02(5.37)$ & 144 & & $-1.29(0.78)$ \\
\hline Week 10 & $11.54(4.33)$ & 45 & & $14.53(5.48)$ & 97 & & $13.58(5.32)$ & 142 & & $-2.48(0.91)^{\star}$ \\
\hline Week 22 & $11.14(5.08)$ & 42 & $0.92(0.42-1.42)$ & $13.39(5.78)$ & 66 & $0.85(0.46-1.24)$ & $12.52(5.60)$ & 108 & $0.88(0.58-1.19)$ & $-1.46(0.95)$ \\
\hline Week 52 & $10.25(5.53)$ & 24 & $0.71(0.05-1.36)$ & $12.62(5.88)$ & 39 & $0.76(0.28-1.25)$ & $11.71(5.82)$ & 63 & $0.74(0.35-1.13)$ & $-1.62(1.24)$ \\
\hline \multicolumn{11}{|l|}{ EQ-5D } \\
\hline Baseline & $0.44(0.30)$ & 56 & & $0.37(0.31)$ & 117 & & $0.39(0.31)$ & 173 & & $0.04(0.04)$ \\
\hline Week 10 & $0.62(0.28)$ & 49 & & $0.48(0.32)$ & 102 & & $0.52(0.31)$ & 151 & & $0.15(0.05)^{*}$ \\
\hline Week 22 & $0.71(0.30)$ & 45 & $1.17(0.71-1.64)$ & $0.56(0.34)$ & 75 & $1.00(0.65-1.34)$ & $0.62(0.33)$ & 120 & $1.06(0.79-1.34)$ & $0.09(0.05)$ \\
\hline Week 52 & $0.73(0.30)$ & 28 & $1.57(0.93-2.22)$ & $0.64(0.33)$ & 42 & $0.97(0.51-1.43)$ & $0.67(0.32)$ & 70 & $1.15(0.78-1.52)$ & $0.08(0.06)$ \\
\hline
\end{tabular}

quality of life during treatment, at treatment termination and at follow-up, with medium to large effect sizes.

At baseline, there were no differences in the scores of the two patient groups for depression severity and other measures. At treatment termination (week 22) and follow-up (week 52) the HRSD and IDS scores for patients with comorbid personality disorder were significantly higher (in other words, they had more symptoms) than for those without personality disorder.

The interpersonal OQ score at treatment termination (week 22) was higher in patients with comorbid personality disorder than in patients without comorbidity. This difference was no longer apparent at follow-up.

By contrast with the depression measurements (HRSD and IDS), there were no differences in the OQ social functioning and EQ-5D scores for the two patient groups at treatment termination and follow-up.

It is striking that there were more non-responders for the $\mathrm{OQ}$ social functioning $\left(\chi^{2}=21.01, P<0.01\right)$ and EQ-5D $\left(\chi^{2}=25.53\right.$, $P<0.01$ ) measures at week 52 than at week 22 .

The analysis of all measurement points together showed a significant time by personality disorder interaction for the HRSD only (estimated mean difference $=0.048$, s.e. $=0.024$ ). Patients without personality disorder improved slightly faster than patients with a personality disorder.

\section{Interaction between personality disorders and treatment condition}

Table 3 shows the mean outcomes at each time point broken down into four groups: depressed patients with or without personality disorder and treatment condition (SPSP or CBT).

In addition, Table 3 shows pre-post treatment and pre-treatment-follow-up effect sizes for both treatment conditions and patient groups. At each time point, multilevel analyses were conducted to determine possible interactions between comorbid personality disorder and treatment condition. The last column shows the multilevel analysis of the interaction.

There was no interaction in observer-rated scores (HRSD) or patient-rated scores (IDS) for depression severity between treatment condition and the presence of comorbid personality disorder at any time point. This indicates that the treatment condition (CBT or SPSP) did not differentially affect depression outcomes for patients with and without comorbid personality disorder. Similar results were found for interpersonal relationships, social functioning and quality of life. In other words, no interaction was found between treatment condition and comorbid personality disorder.

The analysis with time as a continuous variable from baseline to follow-up measurement showed no significant time by treatment condition by personality disorder interactions.

\section{Discussion}

The aim of this study was to examine the effects of comorbid personality disorder on treatment outcomes and 1 year follow-up outcomes of short-term psychotherapy for depression. In addition, we explored differences between depressed patients with and without personality disorder and looked at whether comorbid personality disorder was associated with a different response to SPSP and CBT.

In this study, depressed patients with comorbid personality disorder at baseline had more self-reported depressive symptoms, more previous depressive episodes, and more problems in interpersonal relationships and social functioning than their counterparts without comorbid personality disorder. These findings are in line with other studies ${ }^{29,30}$ which reflect the more chronic and recurrent course of depression in patients with personality disorder: HRSD 


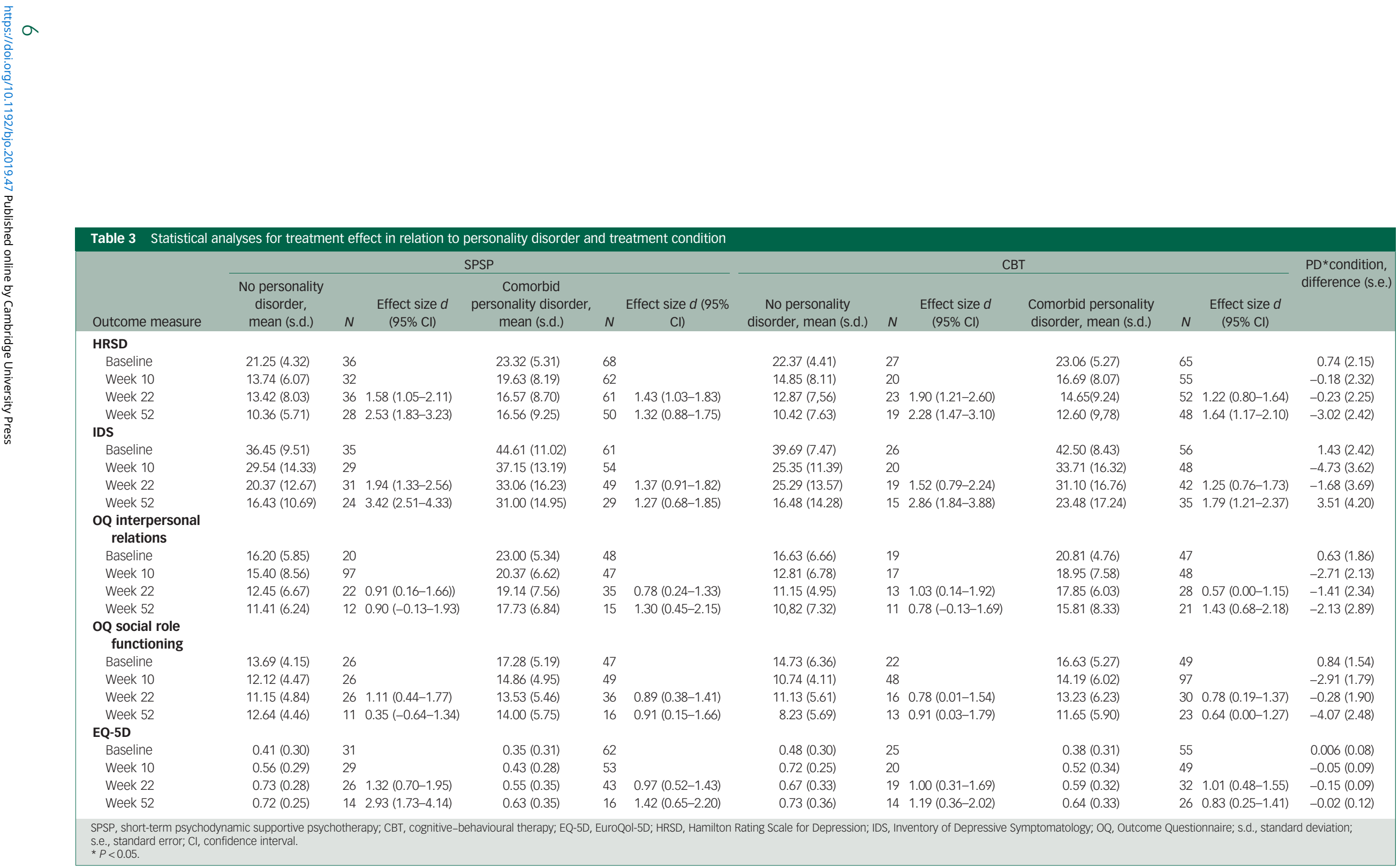


scores in depressed adolescents with comorbid personality disorder are higher than in those without personality disorder. ${ }^{29}$ In addition, higher levels of dysfunction at the symptom level and in social and interpersonal functioning have been found for depressed patients with comorbid personality disorder. ${ }^{30}$

This study shows that the effect sizes were large in the group of patients who had depression but no personality disorder and in the group of patients who had comorbid depression and personality disorder. Furthermore, it is striking that effect sizes actually increased during follow-up irrespective of the presence of personality disorder. This demonstrates the usefulness of short-term treatment in all depressed patients, whether with or without personality disorder. However, despite the fact that patients with comorbid personality disorder improved considerably, we also found that comorbid personality disorder had a clear negative effect.

We performed secondary analyses to determine whether comorbid dysthymia or depression severity had an interaction effect with personality disorder on depression outcome. It emerged that comorbid personality disorder also had a negative effect on outcome, irrespective of the presence of comorbid dysthymia or depression severity. In these additional exploratory analyses of depression severity (estimated mean difference $=2.31$, s.e. $=$ 2.45 ) and dysthymia (estimated mean difference $=1.46$, s.e. $=2.41$ ), we found no interaction with personality disorder.

As Newton-Howes ${ }^{7}$ suggests, a possible explanation for the negative effect of personality disorder on depression outcome is that the focus of both treatments is depression rather than personality disorders. Another explanation could be that the presence of a personality disorder interferes with the establishment of a therapeutic alliance, because the characteristics of personality disorder in particular are related to interpersonal dysfunctions such as problems with working relationships and capacity for intimacy with others. ${ }^{31}$ In turn, a poor therapeutic alliance has a negative effect on treatment outcome. ${ }^{32}$ The implication is that the negative effect of personality disorder on the therapeutic working alliance could affect the treatment outcome negatively. A third potential explanation is that depressed patients with and without personality disorder may have distinct neurobiological features related to, for example, the connectivity between complex brain networks or the function of the amygdala, and that these features may lead to variations in emotional dysregulation. ${ }^{33}$ This factor could explain differential treatment reactions, and the hypothesis could be explored further by including neurobiological parameters in future studies.

By contrast with depression outcome, comorbid personality disorders did not affect social functioning or quality of life at treatment termination or at follow-up. Although social functioning and interpersonal relationships were poorer in personality disorder patients, a similar improvement was achieved in both groups and this appeared to persist through to follow-up. Once again, this underlines the usefulness of short-term approaches and indicates that improvements in these underlying vulnerabilities may be favourable for a future prognosis.

Nevertheless, the differences in impairment between patients with and without personality disorder remain considerable in absolute terms. For instance, the level of social functioning at treatment termination in patients with personality disorder was at the same level as that of patients without personality disorder at the start of treatment.

This suggests that in order to achieve an acceptable result in patients with personality disorder, more intensive and/or prolonged treatment may be required that also addresses the inter- and intrapersonal background of depression. ${ }^{34}$

To our knowledge, studies of the effect of comorbid personality disorders on interpersonal functioning, social role functioning and quality of life are very scarce or heterogeneous. This study found that short-term psychotherapy, irrespective of the treatment modality, leads to improvements in these areas in both patient groups and that personality disorder had no effect at treatment termination other than in the area of interpersonal functioning. This was also found to be the case for social role functioning and quality of life at follow-up.

No interaction was found between treatment condition and personality disorder, indicating that the two treatment modalities are equally effective for both patient groups.

Some other studies have found that personality disorder has different effects in different treatments: Hardy et al ${ }^{30}$ showed that CBT was more effective than psychodynamic-interpersonal psychotherapy for depressed patients with personality disorders. In another study, comorbid personality disorder had a negative effect on depression treatment outcome for patients who received interpersonal psychotherapy, but not for those who received CBT. ${ }^{9}$ Despite these studies and in line with our findings, the review by Newton-Howes ${ }^{7}$ mentioned earlier concluded that the type of treatment does not affect treatment outcomes in the two patient groups.

As SPSP focuses specifically on interpersonal aspects of depression, we had expected problems in interpersonal relationships and social functioning to improve more in the SPSP condition. However, no differences were found between the two conditions in this respect, and it cannot therefore be concluded on the basis of our results that this presumed SPSP working mechanism actually leads to outcomes of the kind we expected.

Although this study showed that short-term psychotherapy led to improvements in depressed patients with comorbid personality disorder at treatment termination and at follow-up, the improvement in depression outcome was less than that in patients without comorbidity, irrespective of the therapy modality. In light of these results, both treatments are an effective first step in a stepped-care approach. However, in addition to the observation already stated here that the focus of therapy on depression does not affect comorbid personality disorders, it may be concluded that the short treatment time and limited treatment sessions may, as claimed by Strandholm et al, ${ }^{29}$ explain why treatment outcomes are worse in the presence of comorbid personality disorders. ${ }^{35}$ More intensive or longer-term forms of psychotherapy could therefore be appropriate for these patient groups.

The current study has a number of limitations. First, the IPDE$\mathrm{SR}$ is a self-report questionnaire for assessing personality disorder that was originally developed as a screening instrument. It cannot be used to formally assess personality disorder diagnoses and it is known to overestimate the prevalence of personality disorder by a factor of 2.5. There is also evidence that state effects, such as depression, may lead to an overreporting of personality disorders; ${ }^{36}$ this may have resulted in even more false positives for personality disorder in this sample. Two-thirds (68\%) of the sample in our study were diagnosed with personality disorder using the IPDE-SR. Elsewhere, however, studies using structured interviews for the assessment of personality disorder have reported lower comorbidity rates: one study ${ }^{29}$ reported a comorbidity rate of $35 \%$, while another ${ }^{30}$ reported $24 \%$. This could indeed indicate that personality disorder was overdiagnosed in the current sample, possibly limiting generalisation to patients with personality disorder in clinical practice. In addition, the overdiagnosis of personality disorder in our sample results in overlapping of the personality disorder diagnosis in different personality disorder clusters. We were therefore unable to differentiate between the three personality disorder clusters in terms of the effect on outcome.

Second, the participants who completed the IPDE-SR and those who did not differed significantly in terms of several characteristics (educational level, prior depressive episodes, living alone, 
employment status, level of income and baseline depression severity). These differences may have affected the representativeness of the patient group studied. However, Mulder $e t a l^{37}$ have reported that neither depression nor demographic characteristics affect depression outcome. Nevertheless, several studies have shown that educational level, ${ }^{38}$ history of depression ${ }^{39}$ and baseline depression severity $^{40}$ are predictors of patients' outcomes after treatment of their depression.

Third, we could not prevent patients from seeking additional treatment during the follow-up period. However, controlling for additional treatment in the follow-up period did not change the general pattern of results.

Fourth, there was no control condition in this study and so we do not know whether the improvement in both patient groups during and after treatment was attributable to the natural course or to the interventions studied.

A strength of this study was the large sample, which allowed us to explore differences between depression with or without comorbid personality disorder, and between CBT and SPSP.

In addition, almost $40 \%$ of the sample consisted of patients with a cultural background that was not north-west European. Treatment was provided in regular psychiatric out-patient clinics, all patients were referred by general practitioners for further treatment, and no selection criteria were used with regard to psychotherapy suitability, personality disorders or previous therapy. All these aspects support the generalisability of the results to daily clinical practice.

In summary, our findings illustrate the usefulness of a shortterm psychotherapeutic approach in a broad group of depressed patients, both with and without a comorbid personality disorder. The effects are maintained over time, but this study also makes clear that patients with comorbid personality disorders need to improve more in the areas of depressive symptoms, interpersonal problems and social functioning in order to reduce susceptibility to recurrence in the future. Further research will be required to determine whether dosage optimisation, duration of psychotherapy, and type of personality disorder or personality disorder cluster affect treatment outcomes in these complex patients.

David Koppers, MSC, Clinical Psychologist and Researcher, Department of Research and Quality of Care, ARKIN Mental Health Institute, the Netherlands; Marit Kool, MSC Clinical Psychologist and Researcher, Department of Personality Disorders, ARKIN Menta Health Institute, the Netherlands; Henricus Van, PhD, MD, Psychiatrist, and Researcher, Department of Personality Disorders, ARKIN Mental Health Institute, NPI, the Netherlands: Ellen Driessen, PhD, Researcher, Department of Research and Quality of Care, ARKIN Mental Health Institute, the Netherlands; Jaap Peen, PhD, Methodologist, Care, ARKIN Mental Health Institute, the Netherlands; Jaap Peen, PhD, Methodo
Department of Research and Quality of Care, ARKIN Mental Health Institute, the Netherlands; Jack Dekker, Head, Department of Research and Quality of Care, ARKIN Mental Health Institute; and Faculty of Behavioural and Movement Sciences, Section Clinical Psychology, Vrije Universiteit, the Netherlands

Correspondence: David Koppers, ARKIN Mental Health Institute, Department of Research and Quality of Care, Klaprozenweg 111, 1033 NN, Amsterdam, the Netherlands. Email: david.koppers@inforsa.nl

First received 30 Jul 2018, final revision 15 May 2019, accepted 4 Jun 2019

\section{References}

1 Cuijpers P, Geraedts AS, Van Oppen P, Andersson G, Markowitz JC, Van Straten A. Interpersonal psychotherapy for depression: a meta-analysis. Am J Psychiatry 2011; 168: 581-92.

2 Driessen E, Smits N, Dekker JJM, Peen J, Don FJ, Kool S, et al. Differential efficacy of cognitive behavioural therapy and psychodynamic therapy for major depression: a study of prescriptive factors. Psychol Med 2016; 46: 731-44.

3 Abbas AA, Kisely SR, Town JM, Leichsenring F, Driessen E, De Maat S, et al. Short-term psychodynamic psychotherapies for common mental disorders (Review). Cochrane Collaboration. Wiley \& Sons, 2014; 7: 1-28.
4 Driessen E, Cuijpers P, De Maat S, Abbas AA, De Jonghe F, Dekker JJM. The efficacy of short-term psychodynamic psychotherapy for depression: a meta-analysis. Clin Psychol Rev 2010; 30: 25-36.

5 Cuijpers P, Karyotaki E, Weitz E, Andersson G, Hollon SD, Van Straten A. The effects of psychotherapies for major depression in adults on remission, recovery and improvement: a meta-analysis. J Affect Disord 2014; 159: 118-26.

6 Friborg O, Martinsen EW, Martinussen M, Kaiser S, Overgard KT, Rosenvinge JH. Comorbidity of personality disorders in mood disorders: a meta-analytic review of 122 studies from 1988 to 2010. J Affect Disord 2014; 152-4: 1-11.

7 Newton-Howes G, Tyrer P, Johnson T, Mulder R, Kool S, Dekker J, et al. Influence of personality on the outcome of treatment in depression: systematic review and meta-analysis. J Personal Disord 2014; 28: 577-93.

8 Harte CB, Hawkins RC. Impact of personality disorder comorbidity on cognitivebehavioral therapy outcome for mood and anxiety disorders: results from a university training clinic. Res Psychother 2016; 19: 124-35.

9 Joyce PR, McKenzie JM, Carter JD, Rae AM, Luty SE, Frampton CMA, et al. Temperament, character and personality disorders as predictors of response to interpersonal psychotherapy and cognitive-behavioural therapy for depression. Br J Psychiatry 2007; 190: 503-8.

10 Steinert C, Hofmann M, Kruse J, Leichsenring F. Relapse rates after psychotherapy for depression-stable long-term effects? A meta-analysis. J Affect Disord 2014; 168: 107-18.

11 Abbass A, Town J, Driessen E. The efficacy of short-term psychodynamic psychotherapy for depressive disorders with comorbid personality disorder. Psychiatry 2011; 74: 58-71.

12 Driessen E, Van HL, Don FJ, Peen J, Kool S, Westra D, et al. The efficacy of cognitive-behavioral therapy and psychodynamic therapy in the outpatient treatment of major depression: a randomized clinical trial. Am J Psychiatry 2013; 170: $1041-50$.

13 De Jonghe F, De Maat S, Van HL, Hendriksen M, Kool S, Van Aalst G, et al. Shortterm psychoanalytic supportive psychotherapy for depressed patients. Psychoanal Inq 2013; 33: 614-25.

14 Molenaar PJ, Don FJ, Van den Bout J, Sterk F, Dekker J. Cognitieve Gedragstherapie bij Depressie. Bohn Stafleu van Loghum, 2009.

15 Beck AT. Cognitive Therapy and the Emotional Disorders. International University Press, 1976.

16 Hamilton M. A rating scale for depression. J Neurol Neurosurg Psychiatry 1960; 23: $56-62$

17 Sheehan DV, Lecrubier Y, Sheehan $\mathrm{KH}$, Amorim $\mathrm{P}$, Janavs J, Weiller $\mathrm{E}$, et al. The Mini-International Neuropsychiatric Interview (M.I.N.I.): the development and validation of a structured diagnostic psychiatric interview for DSM-IV and ICD-10. J Clin Psychiatry 1998; 59: 22-33.

18 Loranger WL, Janca A, Sartorius N. The ICD-10 International Personality Disorder Examination (IPDE). Cambridge University Press, 1994

19 Duijsens IJ, Eurelings-Bontekoe EHM, Diekstra RFW. The VKP, a self-report instrument for DSM-III-R and ICD-10 personality disorders: construction and psychometric properties. Pers Individ Dif 1996; 20: 171-82.

20 Duijsens IJ, Bruinsma M, Jansen SJT, Eurelings-Bontekoe EHM, Diekstra RFW. Agreement between self-report and semi-structured interviewing in the assessment of personality disorders. Personal Individ Dif 1996; 21: 261-70.

21 De Jonghe F. Leidraad voor het scoren van de Hamilton Depression Rating Scale [Hamilton Depression Rating Scale Scoring Manual]. Benecke Consultants, 1994.

22 Bagby RM, Ryder AG, Schuller DR, Marshall MB. The Hamilton depression rating scale: has the gold standard become a lead weight? Am J Psychiatry 2004; 161: 2163-77

23 Rush AJ, Gullion CM, Basco MR, Jarrett RB, Trivedi MH. The inventory of depressive symptomatology (IDS): psychometric properties. Psychol Med 1996; 26: 477-86.

24 Lambert MJ, Burlingame GM, Umphress $V$, Hansen NB, Vermeersch DA Clouse GC. The reliability and validity of the Outcome Questionnaire. Clin Psychol Psychother 1996; 3: 249-58.

25 De Beurs E, Den Hollanders-Gijsma ME, Buwalda V, Trijsbug W, Zitman FG. De Outcome Questionnaire OQ-45. Psychodiagnostisch gereedschap [The Outcome Questionnaire 0Q-45. A psychodiagnostic tool.]. De Psycholoog 2005; 40: 393-400.

26 The EuroQol Group. EuroQol - a new facility for the measurement of healthrelated quality of life. Health Policy 1990; 16: 199-208.

27 Essink-Bot ML, Krabbe PFMM, Bonsel GJM, Aaronson NKP. An empirical comparison of four generic health status measures: the Nottingham health profile, the medical outcomes study 36-item short-form health survey, the COOP/ Wonca charts, and the EuroQol instrument. Med Care 1997; 35: 522-37.

28 Cohen J. Statistical Power Analysis for the Behavioural Sciences (2nd edn). Psychology Press, 1988.

29 Strandholm T, Karlsson L, Kiviruusu O, Pelkonen M, Marttunen M. Treatment characteristics and outcome of depression among depressed adolescent 
outpatients with and without comorbid axis II disorders. J Personal Disord 2014; 28: 853-63.

30 Hardy GE, Barkham M, Shapiro DA, Stiles WB, Rees A, Reynolds S. Impact of cluster $C$ personality disorders on outcomes of contrasting brief psychotherapies for depression. J Consult Clin Psychol 1995; 63: 997-1004.

31 Clarkin JF. An integrated approach to psychotherapy techniques for patients with personality disorder. J Personal Disord 2012; 26(1): 43-62.

32 Hirsh JB, Quilty LC, Bagby RM, et al. The relationship between agreeableness and the development of the working alliance in patients with borderline personality disorder. J Personal Disord 2012; 26(4): 616-27.

33 Klein DN, Bufferd SJ, Ro E, Clark LA. Depression and comorbidity: personality disorders. In The Oxford Handbook of Depression and Comorbidity (eds Richards CS, O'Hara MW): 200-17. Oxford University Press, 2014.

34 Kool M, Van HL, Bartak A, De Maat S, Arntz A, Peen J, et al. Optimizing psychotherapy dosage for comorbid depression and personality disorders (PSYDOS). A pragmatic randomized factorial trial using schema therapy and short-term psychodynamic psychotherapy. BMC Psychiatry 2018; 18: 1-15.

35 Leichsenring F, Rabung S. Long-term psychodynamic psychotherapy in complex mental disorders: update of a meta-analysis. Br J Psychiatry 2011; 199: 15-22.
36 Reich J. The effect of Axis II disorders on the outcome of treatment of anxiety and unipolar depressive disorders: a review. J Personal Disord 2003; 17 387-405.

37 Mulder RT, Joyce PR, Frampton CMA, Luty SE, Sullivan PF. Six months of treatment for depression: outcome and predictors of the course of illness. Am J Psychiatry 2006; 163: 95-100.

38 Van HL. Predicting remission in the outpatient treatment of major depressive disorders. In Exploring Predictive Factors in Depression Treatment. The Role of Patient Characteristics and Psychodynamic Diagnosis: 43-58. Ridderprint Offsetdrukkerij BV, 2008

39 Colman I, Naicker K, Zeng Y, Ataullahjan A, Senthilselvan A. Predictors of longterm prognosis of depression. CMAJ 2011; 183: 1969-76.

40 Anderson G, Bergström J, Holländare F, Ekselius L, Carlbring P. Delivering cognitive behavioural therapy for mild to moderate depression via the internet: predicting outcome at 6-month follow-up. Verhaltenstherapie 2004; 14: 185-89. 